\title{
Electrodeposited ZnO@three-dimensional Graphene Composite Modified Electrode for Electrochemistry and Electrocatalysis of Myoglobin
}

\author{
Zuorui Wen ${ }^{1}$, Wenshu Zhao ${ }^{1}$, Xiaoyan Li $^{1}$, Xueliang Niu ${ }^{1}$, Xiuli Wang $^{2}$, Lijun Yan ${ }^{1}$, Xi Zhang ${ }^{1}$, \\ Guangjiu $\mathrm{Li}^{2}$, Wei Sun ${ }^{1 *}$ \\ ${ }^{1}$ Key Laboratory of Tropical Medicinal Plant Chemistry of Ministry of Education, College of \\ Chemistry and Chemical Engineering, Hainan Normal University, Haikou 571158, P R China \\ ${ }^{2}$ College of Chemistry and Molecular Engineering, Qingdao University of Science and Technology, \\ Qingdao 266042, P. R. China \\ *E-mail: swyy26@ hotmail.com
}

doi: $10.20964 / 2017.03 .09$

Received: 24 November 2016 / Accepted: 4 January 2017 / Published: 12 February 2017

\begin{abstract}
A three-dimensional graphene (3DGR) was electrodeposited on carbon ionic liquid electrode (CILE) and further decorated with electrodeposited zinc oxide $(\mathrm{ZnO})$ to get a $\mathrm{ZnO} @ 3 \mathrm{DGR}$ hybrid composite. Then myoglobin $(\mathrm{Mb})$ was immobilized on the surface of $\mathrm{ZnO} @ 3 \mathrm{DGR}$ modified electrode with Nafion to prepare the biosensor named as Nafion/Mb/ZnO@3DGR/CILE. On cyclic voltammogram a pair of well-defined redox responses resulted from the electron transfer of $\mathrm{Mb}$ with the working electrode was got, which could be ascribed to the specific characteristics of ZnO@3DGR including porous macrostructure, biocompatibility, high conductivity and big surface area. Electrochemical parameters including the electron transfer coefficient $(\alpha)$ and the apparent heterogeneous electron transfer rate constant $\left(k_{\mathrm{s}}\right)$ were got by electrochemical methods with the values as 0.31 and $0.76 \mathrm{~s}^{-1}$. This biosensor showed excellent electrocatalysis to the electro reduction of trichloroacetic acid (TCA). A good linear relationship between the catalytic reduction peak current and TCA concentration was in the range from 0.5 to $30.0 \mathrm{mmol} \mathrm{L}^{-1}$ and the detection limit was $0.167 \mathrm{mmol} \mathrm{L}^{-1}(3 \sigma)$. The results indicated that a third-generation electrochemical Mb biosensor with ZnO@3DGR/CILE was prepared and exhibited good stability with reproducibility.
\end{abstract}

Keywords: Three-dimensional graphene; $\mathrm{ZnO}$; Myoglobin; Carbon ionic liquid electrode; Electrochemistry; Electrocatalysis.

\section{$\underline{\text { FULL TEXT }}$}


(C) 2017 The Authors. Published by ESG (www.electrochemsci.org). This article is an open access article distributed under the terms and conditions of the Creative Commons Attribution license (http://creativecommons.org/licenses/by/4.0/). 